\title{
Thermal ablation of colorectal liver metastases: a position paper by an international panel of ablation experts, the interventional oncology sans frontières meeting 2013
}

\author{
Alice Gillams ${ }^{1} \cdot$ Nahum Goldberg ${ }^{2} \cdot$ Muneeb Ahmed $^{2} \cdot$ Reto Bale $^{3} \cdot$ David Breen $^{4}$. \\ Matthew Callstrom $^{5}$ • Min Hua Chen ${ }^{6}$ - Byung Ihn Choi ${ }^{7}$. Thierry de Baere ${ }^{8}$. \\ Damian Dupuy $^{9}$ - Afshin Gangi ${ }^{10}$ - Debra Gervais ${ }^{11}$ - Thomas Helmberger $^{12}$. \\ Ernst-Michael Jung $^{13}$ • Fred Lee ${ }^{14}$ • Riccardo Lencioni ${ }^{15}$ • Ping Liang ${ }^{16}$ • \\ Tito Livraghi $^{17}$ - David Lu ${ }^{18}$ - Franca Meloni ${ }^{19}$ - Philippe Pereira ${ }^{20}$ - Fabio Piscaglia ${ }^{21}$. \\ Hyunchul Rhim ${ }^{22} \cdot$ Riad Salem $^{23}$ - Constantinos Sofocleous ${ }^{24} \cdot$ Stephen B. Solomon $^{24}$. \\ Michael Soulen $^{25} \cdot$ Masatoshi Tanaka ${ }^{26} \cdot$ Thomas Vogl $^{27} \cdot \operatorname{Brad~Wood~}^{28}$. \\ Luigi Solbiati $^{29}$
}

Received: 18 September 2014 /Revised: 2 February 2015 / Accepted: 7 April 2015 /Published online: 22 May 2015 (C) The Author(s) 2015. This article is published with open access at Springerlink.com

\begin{abstract}
Objectives Previous attempts at meta-analysis and systematic review have not provided clear recommendations for the clinical application of thermal ablation in metastatic colorectal cancer. Many authors believe that the probability of gathering randomised controlled trial (RCT) data is low. Our aim is to provide a consensus document making recommendations on
\end{abstract}

the appropriate application of thermal ablation in patients with colorectal liver metastases.

Methods This consensus paper was discussed by an expert panel at The Interventional Oncology Sans Frontières 2013. A literature review was presented. Tumour characteristics, ablation technique and different clinical applications were considered and the level of consensus was documented.
Alice Gillams

alliesorting@gmail.com

1 Imaging Department, The London Clinic, 20 Devonshire Place, London W1G 6BW, UK

2 Beth Israel Deaconess Medical Centre, Boston, MA, USA

3 Innsbruck University Hospital, Innsbruck, Austria

4 Southampton University Hospital, Southampton, UK

5 The Mayo Clinic, Rochester, MN, USA

6 Peking University Hospital, Beijing, China

7 Seoul University Hospital, Seoul, Korea

8 Gustave Roussy Cancer Campus, Paris, France

9 Rhode Island, RI, USA

10 University of Strasbourg, Strasbourg, France

11 Massachusetts General Hospital, Boston, MA, USA

12 Klinikum Bochenhausen, Munich, Germany

13 University of Regensburg, Regensburg, Germany
University of Wisconsin, Madison, WI, USA

University of Pisa, Pisa, Italy

Chinese PLA General Hospital, Beijing, China

Clinical Institute Humanitas, Rozzano Milano, Milan, Italy

UCLA, Los Angeles, CA, USA

University of Milan, Milan, Italy

University of Heidelberg, Heidelberg, Germany

University of Bologna, Bologna, Italy

Sungkyunkwan University, Seoul, Korea

Northwestern University, Chicago, IL, USA

Memorial Sloane Kettering, New York, NY, USA

University of Pennsylvania, Philadelphia, PA, USA

Yokokura Hospital, Miyama, Japan

University of Frankfurt, Frankfurt, Germany

National Institute for Health, Bethesda, MD, USA

Busto Arsizio, Italy 
Results Specific recommendations are made with regard to metastasis size, number, and location and ablation technique. Mean $31 \%$ 5-year survival post-ablation in selected patients has resulted in acceptance of this therapy for those with technically inoperable but limited liver disease and those with limited liver reserve or co-morbidities that render them inoperable.

Conclusions In the absence of RCT data, it is our aim that this consensus document will facilitate judicious selection of the patients most likely to benefit from thermal ablation and provide a unified interventional oncological perspective for the use of this technology.

Key Points

- Best results require due consideration of tumour size, number, volume and location.

- Ablation technology, imaging guidance and intraprocedural imaging assessment must be optimised.

- Accepted applications include inoperable disease due to tumour distribution or inadequate liver reserve.

- Other current indications include concurrent co-morbidity, patient choice and the test-of-time approach.

- Future applications may include resectable disease, e.g. for small solitary tumours.

Keywords Colorectal neoplasms · Liver neoplasms · Ablation techniques $\cdot$ Consensus $\cdot$ Clinical protocols

\section{Introduction}

Colorectal cancer is the second most common cause of cancer death in developed countries and the third most common malignancy worldwide [1]. Fifty percent of patients develop liver metastases yet only a minority (10-15\%) can undergo hepatic resection. Five-year survival following liver resection ranges between $31 \%$ and $58 \%$ in carefully selected patients $[2,3]$. The remainder are usually offered chemotherapy and/or local tumour ablation. Median survival following systemic treatment is now of the order of 20-22 months in patients who receive biological agents and multiple sequential chemotherapy regimes, 5 -year survival remains close to $0 \%$. Five-year survival following ablation varies between $17 \%$ and $51 \%$ (Table 1). Our aim is to present a consensus paper with recommendations on how radiofrequency and other types of thermal ablation should be built into the overall management plan of patients with colorectal liver metastases. The need for robust long-term follow-up data meant that this paper concentrated on radiofrequency (RF) ablation, the only thermal ablation source at present with substantial follow-up literature. RF ablation was first performed in the early 1990s and in the first few years there were a number of significant changes in technology which resulted in improved ablation efficacy $[8,9]$. By the late 1990s and early 2000s ablation was becoming accepted in the interventional radiology community but was still viewed with some scepticism by the oncology and surgical communities. The first few surgical papers from the early 2000s reflect this, but more recently there has been genuine enthusiasm for a technique that can deliver effective focal therapy to many more patients than could be treated with resection alone [10-12]. The effectiveness and the limitations of RF ablation are now well understood. The question of where ablation fits in the overall management of patients with metastatic colorectal cancer is still being debated. In the last few years there have been numerous reviews of the ablation literature [13-26]. All of these have concluded that there is insufficient data, in particular randomised controlled trial (RCT) data, and as a result have had difficulty providing recommendations on the role of ablation. Attempts at RCT have not been successful due to difficulties in randomisation, crossover between treatment arms, changes in chemotherapy regimes and expense. However, many ablation practitioners and early pioneers feel that the field has sufficiently matured for initial recommendations to be made. The following consensus document was discussed at a meeting of ablation experts which included more than 25 interventional oncologists, from around the world, all of whom had substantial personal experience in liver ablation.

\section{Materials and methods}

An initial draft was prepared for discussion and circulated prior to The International Oncology Sans Frontières Congress 2013. This document was then discussed and specific recommendations were made. Each recommendation, such as tumour size, was put to a vote, by an open show of hands. The document was then modified and disseminated electronically for comment. Feedback on subsequent versions was received from all authors. Each recommendation is accompanied with a description of the level of consensus achieved. Where there was consensus among all or nearly all (>95\%) members, the consensus level is described as strong. Where the majority ( $>80 \%$ of experts) but not all agreed, the level of consensus is described as moderate. Only recommendations where $>80 \%$ consensus was achieved are included.

These guidelines are based on experience with radiofrequency ablation as the need for long-term follow-up data meant that there was insufficient data for some of the newer technologies, such as microwave (MW) and irreversible electroporation (IRE). Cryoablation and laser ablation are not widely implemented in colorectal liver metastases and again the data is limited. When more data, for example from high power MW, becomes available a revision of the current recommendations will be considered. 


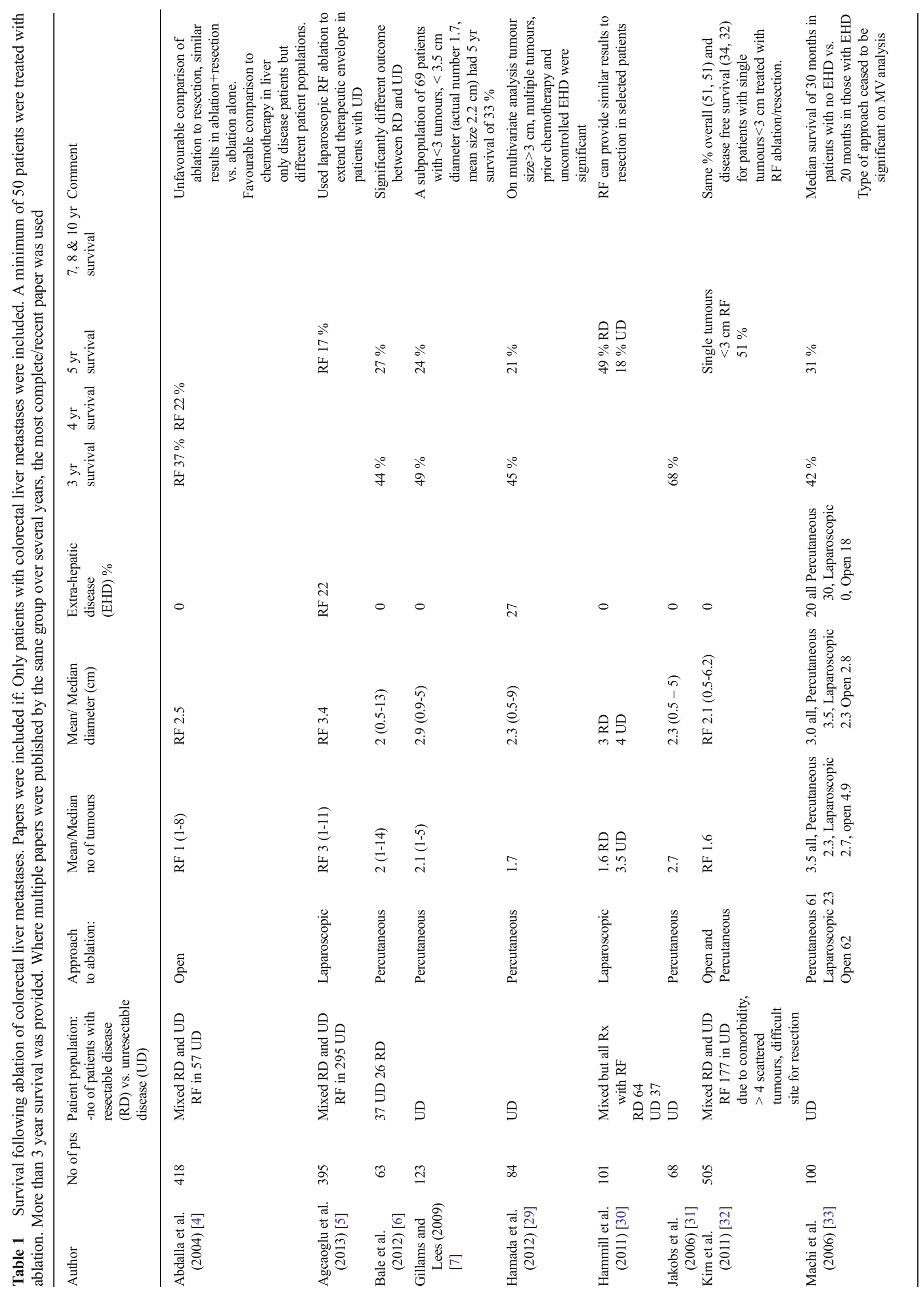




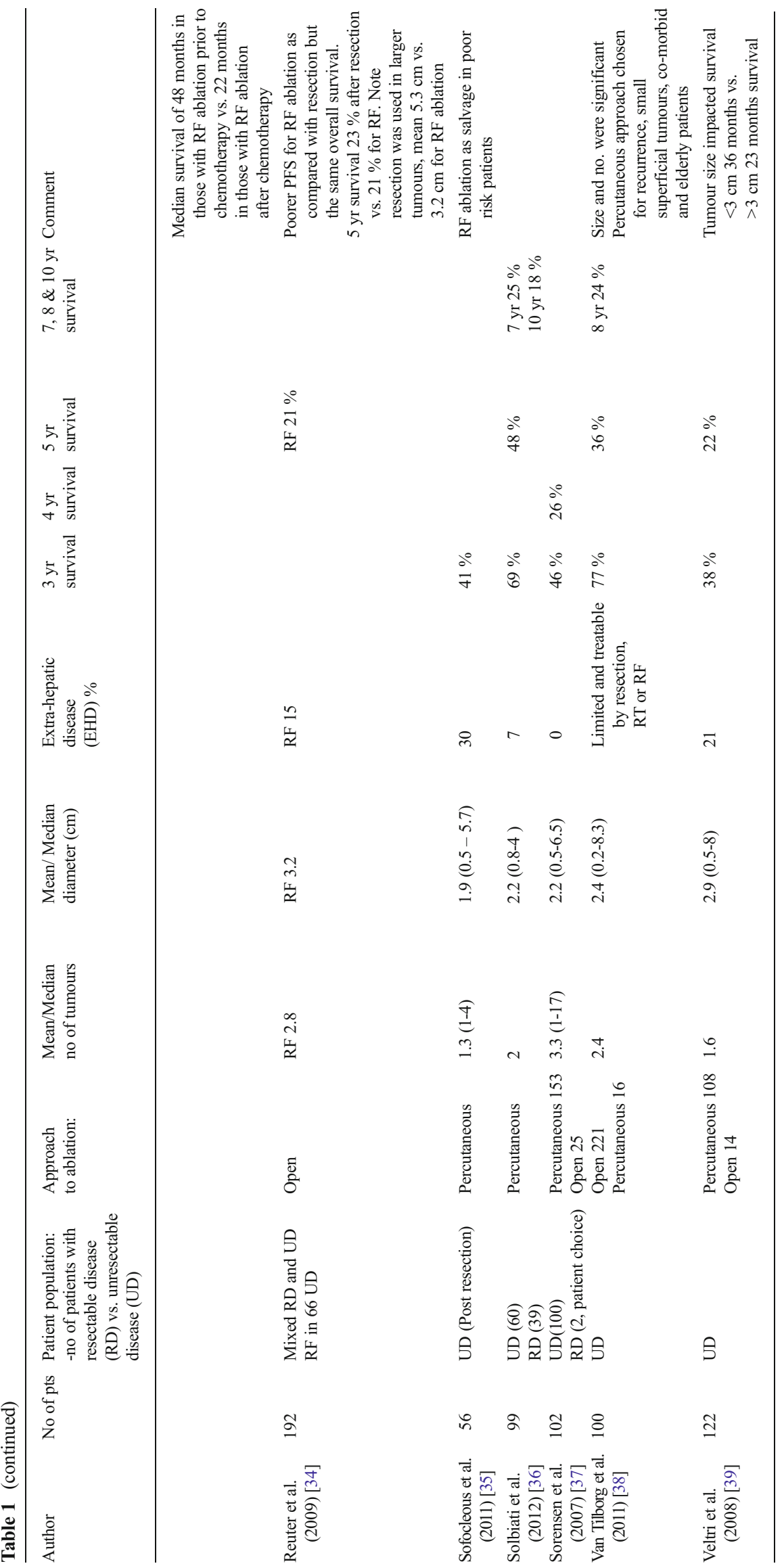




\section{Literature review}

A PubMed search of the literature from 1998 to March 2013 using the search terms: colorectal and ablation; treatment and colorectal liver metastases; radiofrequency ablation and liver metastases; ablation and liver metastases, produced in excess of 5000 results. These were further refined by only including papers specifically related to colorectal liver metastases and radiofrequency ablation technology with a defined minimum length of follow-up and minimum numbers of patients. The rationale for this was that all new techniques and procedures have an intrinsic learning curve. This was well studied at the time of introduction of laparoscopic cholecystectomy and again for laparoscopic-assisted colectomy and has also been shown to be true of ablation [27, 28]. Mulier estimated that treatment of at least 100 liver tumours was required for the mastery of RF ablation [28]. Accordingly, in most series the mean number of tumours treated per patient is two, and therefore series with a minimum of 50 patients (i.e. approximately 100 tumours in total) with colorectal liver metastases treated with RF and 3-year follow-up were included in the survival analysis (Table 1) [4-7, 29-39]. Furthermore, papers that did not separate the results of ablation with or without resection were not included, as this confounding variable could potentially obscure results. To avoid duplication of reporting, for those centres with multiple publications over many years, the most recent or most comprehensive report was selected. Abstracts were not included as this format does not provide sufficient detail for the study to be analysed.

All authors defined patients as having resectable or unresectable disease and RF ablation was almost without exception applied to patients with unresectable disease; details of the population have been specified. Of the 15 papers, four used both open and percutaneous approaches, two open only, two laparoscopic only, six percutaneous only and one used all three approaches. Four of the papers included resection, ablation and combined resection and ablation data. For our survival analysis we have shown the results from the ablation subgroup.

\section{Survival analysis}

The total population of patients who underwent RF ablation from the 15 papers was 1613 . Mean tumour number per patient was $2.2(1-3.5)$ and mean tumour size $2.6 \mathrm{~cm}(1.7-4)$. Eight papers included patients with extra-hepatic disease but one specified that all sites of extrahepatic disease were potentially treatable by resection, radiotherapy or ablation. The mean 3-year survival from the date of first thermal ablation was $50 \%(37-77 \%$ ) and the mean 5-year survival was $31 \%$ (17-51\%). Nearly all studies used RF ablation in patients with unresectable disease, but when ablation was applied to patients with potentially resectable disease the 5 -year survival increased to $50 \%$. The mean 5 -year survival for the percutaneous, laparoscopic and open approaches were $30 \%, 28 \%$ and $21 \%$, respectively.

Table 2 shows a summary of morbidity, mortality and hospital stay for the percutaneous, laparoscopic and open approaches with comparison to resection and combined resection and ablation. Table 3 shows the local recurrence rates according to procedural approach and size of tumour ablated.
Table 2 Mortality, morbidity and hospital stay

\begin{tabular}{llll}
\hline Category & Mortality, $\%$ & $\begin{array}{l}\text { Major complications, } \\
\%\end{array}$ & $\begin{array}{l}\text { Hospital stay, mean days } \\
\text { (range) }\end{array}$ \\
\hline Open resection & $1-5[4,5]$ & $25-30[37]$ & $13(5-55)[40]$ \\
& $21[32]$ & $13.4[32]$ \\
Combined open RF & $4.5[40]$ & $37[32]$ & $9.8[34]$ \\
$\quad$ ablation+resection & & $32[40]$ & $15[32]$ \\
Open RF ablation & $2.3[41]$ & $32[41]$ & \\
& $1.1[42]$ & $10[34]$ & $6.6[34]$ \\
Laparoscopic & $0.0[34]$ & $9.6[42]$ & $4.2[32]$ \\
RF ablation & $0.3[5]$ & $4.4[5]$ & $3.3[30]$ \\
Percutaneous & $0.0[30]$ & $3.1[30]$ & $2(1-9)[40]$ \\
RF ablation & $0.0[7,29,31,35-37]$ & $4.7[7]$ & $1.3[43]$ \\
& $4.0[35]$ & $1.0[7]$ \\
& & $2.2[29]$ & \\
& & $1.3[36]$ & \\
\hline
\end{tabular}

$R F$ radiofrequency 
Eur Radiol (2015) 25:3438-3454

3443

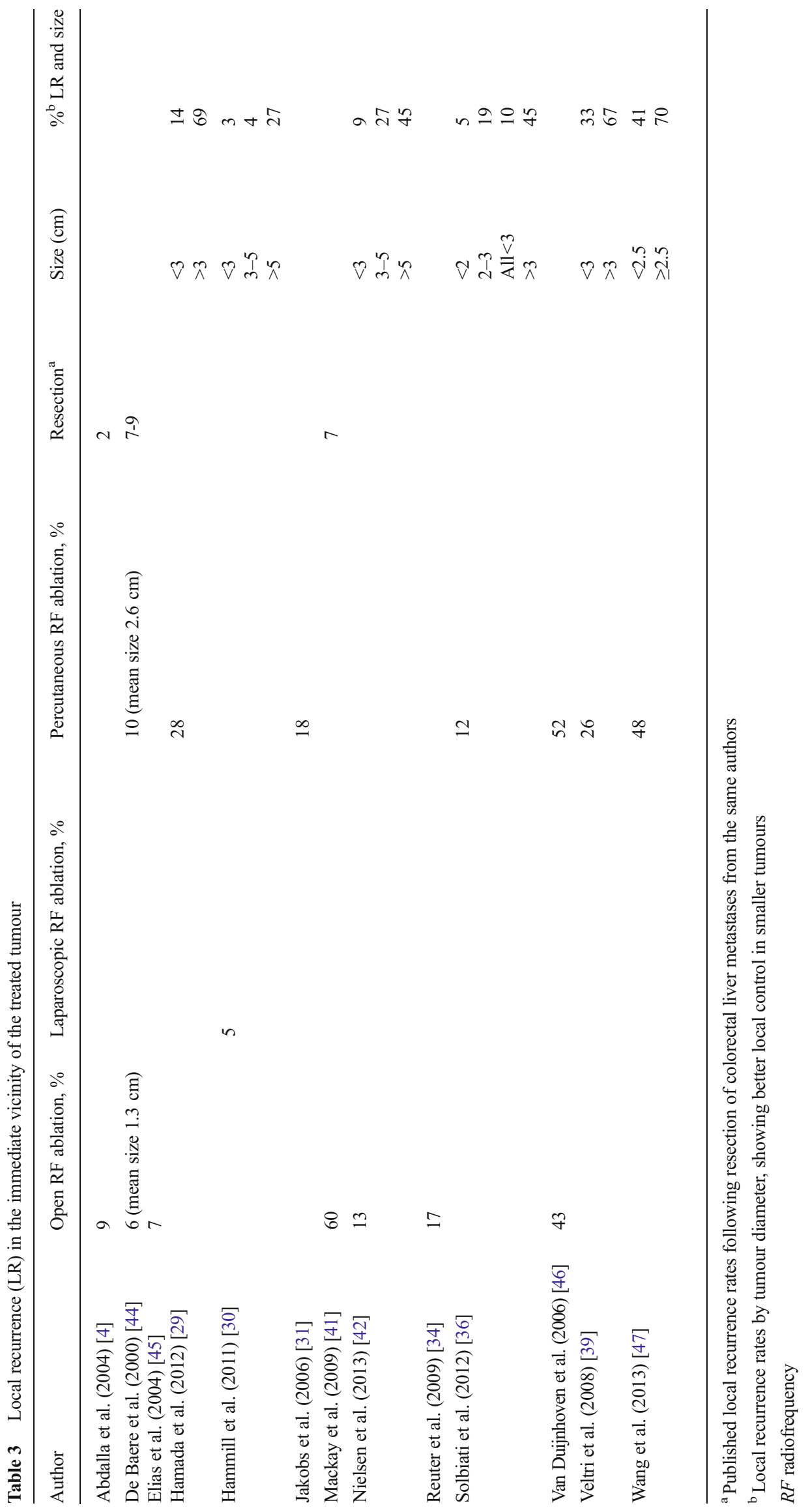

Springer 


\section{Recommendations - tumour and technique specific considerations (Table 4)}

\section{Tumour size (maximum longitudinal diameter in the axial plane (cm))}

Thermal ablation is particularly effective in treating smallto medium-sized tumours. Many series report attempts at treating tumours larger than $5 \mathrm{~cm}$ in diameter, even up to 11 or $12 \mathrm{~cm}$, but the incomplete ablation rate and local recurrence rate for these large tumours is very high and so these patients are better served by other treatment modalities. Analysis of local recurrence rates and survival shows an advantage for small tumours. These are detailed in Table 3 where consistently lower local tumour progression is reported with reducing tumour size. The most common cut-off point is $3 \mathrm{~cm}[29,30,36,39]$. However, tumours up to $5 \mathrm{~cm}$ can be completely ablated and permanently eradicated depending on their anatomical position and the treatment protocol used. For example, Hammil et al. [30] reported a $3 \%$ local recurrence rate for $<3-\mathrm{cm}$ tumours and a $4 \%$ recurrence rate for 3 - to $5-\mathrm{cm}$ tumours. Recurrence rates for $>5 \mathrm{~cm}$ tumours ranges from 27 $45 \%$ and so thermal ablation with curative intent is not generally recommended for metastases $>5 \mathrm{~cm}[30,42]$.

The consensus was that smaller, $<3 \mathrm{~cm}$, tumours are more straightforward to treat than larger tumours, but that well located tumours $<5 \mathrm{~cm}$ can be effectively treated depending on their anatomical position and the treatment protocol used. Well located tumours are defined as those with easy access, located such that clear margins can be achieved.

Consensus level: strong.

\section{Tumour number}

As ablation is a focal, minimally invasive technique, there is a limit to the number of tumours that can be successfully treated. Most centres will accept patients with five tumours or less. Some centres treat up to nine tumours, if the maximum diameter is $<4 \mathrm{~cm}$, and usually at two treatment sessions [48, 49]. As in the resection literature, the best results are achieved in solitary tumours, Gillams et al. [32] reported 3-year survival in excess of $80 \%$ and Kim et al. [50] reported 5-year survival of $51 \%$ in solitary tumours. Additional tumours that develop during follow-up, including new tumours in the postresection liver remnant or local recurrence, should be considered for ablation based upon anatomical and size criteria.

The consensus was that patients with five or fewer tumours should routinely be considered for ablation and that patients with nine or fewer tumours should be considered in selected cases.

Consensus level: strong.

\section{Overall liver tumour volume}

In addition to the size and number of individual tumours, the overall liver tumour volume is also important. For example, in the EORTC 4004 (CLOCC) trial patients with nine or fewer tumours were treated, but the maximum individual tumour diameter allowed was $4 \mathrm{~cm}$ [49]. A crude overall liver tumour volume can be calculated from the product of the mean maximum tumour size and mean number. Analysis of the 5-year survival in four papers where patients without extra-hepatic disease were treated shows a direct correlation between crude liver tumour volume and survival with the best results in those with small volume disease $\left(R^{2} 0.7\right)$ (Fig. 1) $[7,30,32,38]$. We would therefore recommend that in addition to size and

Table 4 Summary of recommendations. Tumour and technical considerations

\begin{tabular}{|c|c|c|}
\hline Parameter & Preferred & Caveat \\
\hline Tumour size & $<3 \mathrm{~cm}$ & Well located tumours $<5 \mathrm{~cm}$ may be suitable for ablation \\
\hline Tumour number & $1-3$ optimal, $<5$ preferable & 6-9 maximum \\
\hline $\begin{array}{l}\text { Tumour location next to } \\
\text { major bile ducts }\end{array}$ & Avoid & $\begin{array}{l}\text { Consider high flow biliary cooling via nasobiliary tubes } \\
\text { or other non-thermal interventional oncology techniques }\end{array}$ \\
\hline $\begin{array}{l}\text { Tumours located in contact w } \\
\text { ith blood vessels }\end{array}$ & $\begin{array}{l}\text { Suitable for ablation with careful follow-up } \\
\text { and repeat treatment if necessary }\end{array}$ & $\begin{array}{l}\text { Consider more intensive RF ablation to compensate for } \\
\text { blood flow cooling, could consider IRE or MW }\end{array}$ \\
\hline $\begin{array}{l}\text { Tumours located within } 1 \mathrm{~cm} \text { of } \\
\text { vulnerable structures, e.g. colon }\end{array}$ & $\begin{array}{l}\text { Require displacement from the ablation } \\
\text { zone using adjunctive measures, e.g. } \\
\text { percutaneous hydro- or gas-dissection }\end{array}$ & $\begin{array}{l}\text { Laparoscopic approach if adequate separation cannot } \\
\text { be achieved percutaneously }\end{array}$ \\
\hline Extra-hepatic disease (EHD) & $\begin{array}{l}\text { Suitable for liver ablation as long as all sites } \\
\text { of EHD disease are radically treated }\end{array}$ & $\begin{array}{l}\text { Palliative liver ablation in patients with more extensive } \\
\text { EHD is not recommended }\end{array}$ \\
\hline $\begin{array}{l}\text { Local recurrence should } \\
\text { be minimised by: }\end{array}$ & $\begin{array}{l}\text { 1. Achieving }>1 \mathrm{~cm} \text { ablation margins in } 3 \mathrm{D} \\
\text { 2. Maximising operator experience } \\
\text { 3. GA should be available as required } \\
\text { 4. Optimal definition of the tumour } \\
\text { 5. Optimal intra-procedural assessment } \\
\text { of the ablation zone }\end{array}$ & $\begin{array}{l}\text { Conscious sedation procedures are an acceptable alternative } \\
\text { in unfit patients }\end{array}$ \\
\hline
\end{tabular}


Fig. 1 Crude tumour volume (product of mean size and mean number of liver metastases) vs. 5 -year survival

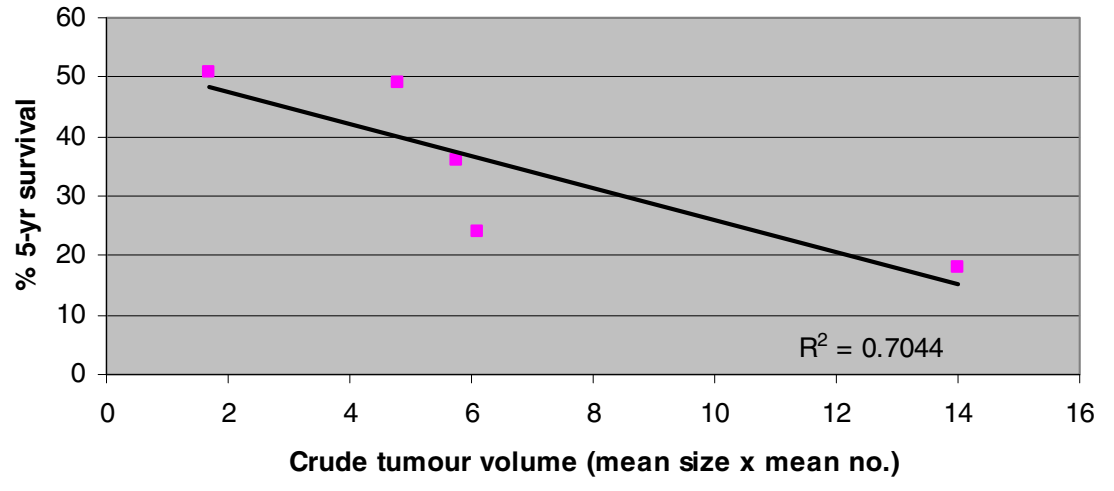

number of tumours, the total liver tumour volume is taken into consideration.

Consensus level: strong

\section{Relationship to central bile ducts}

Ablation to within $1 \mathrm{~cm}$ of the major bile ducts (common bile duct, common hepatic, right and left hepatic ducts) runs the risk of bile duct injury [51]. The secondary effects, cholangitis and liver abscesses can be very significant, particularly if the patient requires chemotherapy at some later date. Therefore thermal ablation in this area is not recommended unless the bile ducts can be effectively protected. There is limited data suggesting high-flow bile duct cooling, for example via a nasobiliary tube, is effective in protecting the bile ducts [52]. Alternative techniques such as IRE, stereotactic body radiotherapy or transarterial therapies could be considered [53]. The consensus is that central bile ducts must be effectively protected or alternative technologies sought.

Consensus level: strong

\section{Relationship to blood vessels}

Ablation of tumours next to blood vessels is more difficult due to the cooling effect of blood flow. Ablation can be applied to tumours in contact with larger vessels ( $>3 \mathrm{~mm}$ in diameter) accepting an increased risk for tumour recurrence and the need for more than one treatment. This well known phenomenon has not been quantified in detail, but the risk of recurrence varies with the size of the vessel, the ablation technology and the length of vessel contact with the tumour. Strategies to ablate more vigorously next to blood vessels have been successfully adopted by many centres but are not part of standard commercial protocols. These strategies include increased power or duration of ablation next to the vessel or preferential placement of applicators towards the vessel side of the tumour. The patient and referring clinician should be advised as to the possible need for repeat treatment and the necessity of appropriate follow-up to detect and treat early tumour re-growth and so control the liver tumour load. Alternative technologies, for example microwave and IRE, may also have a role [54].

Consensus level: strong

\section{Proximity to vulnerable structures}

Ablation in close proximity to vulnerable structures, such as the colon, requires measures to create an acceptable safety margin or an operative approach [40]. Percutaneous hydro/ gas dissection is a simple and very effective technique and should be part of the routine armamentarium of any ablation practice [55-57].

Consensus level: strong

As size, number and location are all important features, there is a strong consensus that these three factors should be considered in concert when evaluating the appropriateness of ablation in any given patient.

\section{Patients with small volume, ablatable liver metastases and extra-hepatic disease}

Patients with extra-hepatic disease can be divided into those with limited, treatable extra-hepatic disease, by resection, ablation or radical radiotherapy, and those with more extensive disease for which the only treatment option is chemotherapy. The first group can benefit from ablation in the liver if the primary site and others sites of extra hepatic disease are radically treated, for example ablation of small volume lung metastases [58-60]. Liver ablation in patients with more extensive extra-hepatic disease is of uncertain value. There is a wide range of survival reported for this group depending on volume of disease, sites involved, chemotherapy regimen and response, but in one paper the 5-year survival for 85 patients who had extrapulmonic, extra-hepatic disease but limited liver disease treated with liver ablation was only $3 \%$ [7]. The optimal ablation patient, as for resection, has disease limited to the liver.

Consensus level: strong

\section{Maximising local tumour control}

Many studies show higher local recurrence rates after ablation than after resection (Table 3). The ease of repeated treatment, particularly by the percutaneous approach, compensates to a 
degree for the higher local recurrence rate. This was confirmed in a study by Otto et al. [61] where RF ablation was performed as first-line treatment for smaller tumours, median $3 \mathrm{~cm}$ (range $1-5 \mathrm{~cm})$, and resection was used for larger tumours, median $5 \mathrm{~cm}$ (range $1-14 \mathrm{~cm}$ ). The estimated 5-year survival was similar: $48 \%$ for ablation and $51 \%$ for resection. The local recurrence rate was higher following ablation but there were more options for repeat intervention (either surgery or ablation) for new or recurrent disease, an important feature as most stage IV cancer patients will have multiple metastatic events. Similarly, Reuter et al. [34] showed different rates of diseasefree progression between the resection and ablation group but overall survival was the same. Nevertheless, it is still of major importance to get good local tumour control (i.e. $<5 \%$ local tumour progression) and ideally percutaneous ablation would provide both excellent local tumour control and the option for repeated treatments for new metastases.

In addition to the factors already discussed such as tumour size, what else should we do to maximise local tumour control?

a. Obtaining adequate ablative margins is essential (strong consensus)

Colorectal liver metastases are less well perfused than the surrounding liver so it is easier to ablate to the tumour edge than to ablate the normally perfused liver around the metastasis which is required in order to achieve an ablative margin [62]. Applicators need to be positioned specifically to achieve a margin. A minimum 1-cm ablation margin is required in all directions or to the edge of the liver to maximise the likelihood of complete ablation. Greater than 1-cm margins further reduces the likelihood of local tumour progression [47]. Margins are particularly important where tumour definition is poor, for example in downsized tumours following chemotherapy.

b. Excellent definition of the extent of the tumour is required (strong consensus)

Contrast-enhanced imaging is recommended. Several studies show high local tumour recurrence rates where un-enhanced ultrasound (US), un-enhanced computed tomography (CT) or CT fluoroscopy have been used [29, 39, 46, 47].

c. Operator experience (strong consensus)

Experience with performing a minimum of 100 liver tumour ablations has been correlated with decreased recurrence rates. Each ablation technology/device has a different set of properties. Limited experience with multiple different devices is particularly unhelpful as it further dilutes the operator experience.

d. General anaesthesia (GA) (strong consensus)

The use of GA increases the rate of complete ablation [28]. Consequently GA should be freely available to be used at the discretion of the interventional oncologist. In patients who are not fit enough for GA, a moderate conscious sedation procedure is a valid option [63]. e. Pre-procedural assessment scans should be less than 2 weeks old (strong consensus)

The mean volume doubling time of colorectal liver metastases is 100 days therefore recent studies are needed for patient selection. Detailed confirmatory imaging at the time of treatment will facilitate complete ablation.

f. Monitoring ablation results at the time of treatment using contrast-enhanced CT, MRI or US and performing more ablation as needed, with further applicator insertions, higher power or additional treatment duration, at the same session will increase the chances of complete ablation with adequate margins in all dimensions. We therefore strongly recommend contrast-enhanced intra-procedural CT, MRI or US [64] (strong consensus).

\section{Current clinical Indications for thermal ablation (Fig. 2, Table 5)}

\section{Patients with non-resectable disease due to number and distribution of metastases should receive ablation \pm chemotherapy instead of systemic chemotherapy alone}

The last 15 years have seen a marked improvement in both response rates and survival following systemic chemotherapy. Median survival is now of the order of 20-22 months in patients who receive biological agents and multiple sequential chemotherapy regimes [65]. Nevertheless, 5-year survival is close to $0 \%$ unless patients can undergo and benefit from surgery. RF ablation has been successfully applied in patients with non-resectable, small-volume liver disease, often in conjunction with chemotherapy, and this has resulted in 3-year survival rates of 37-77 \% and 5-year survival rates of 17 $51 \%$ (Table 1) [4-7, 29-39]. Abdalla compared ablation in unresectable patients with chemotherapy in un-ablatable patients, all with liver-only disease, and showed a significant improvement in survival in the ablation group median survival: 25 months versus 16.5 months $(p=0.005)$ [4]. Even though in this study RF ablation was applied to a different population than those receiving chemotherapy alone, who may have had more numerous or larger tumours, both groups had liver-only disease at surgical staging, had potentially curable disease on pre-operative staging, and were sufficiently fit to undergo major surgery, thus many consider that this marked improvement in survival in the RF ablation group is likely to reflect a benefit.

There has been one RCT (EORTC 4004, CLOCC trial) which aimed to study the benefit of adding ablation to systemic chemotherapy in patients with initially inoperable metastases. Inevitably there was an element of cross-over, so $5 / 59(8.5 \%)$ of those in the non- 


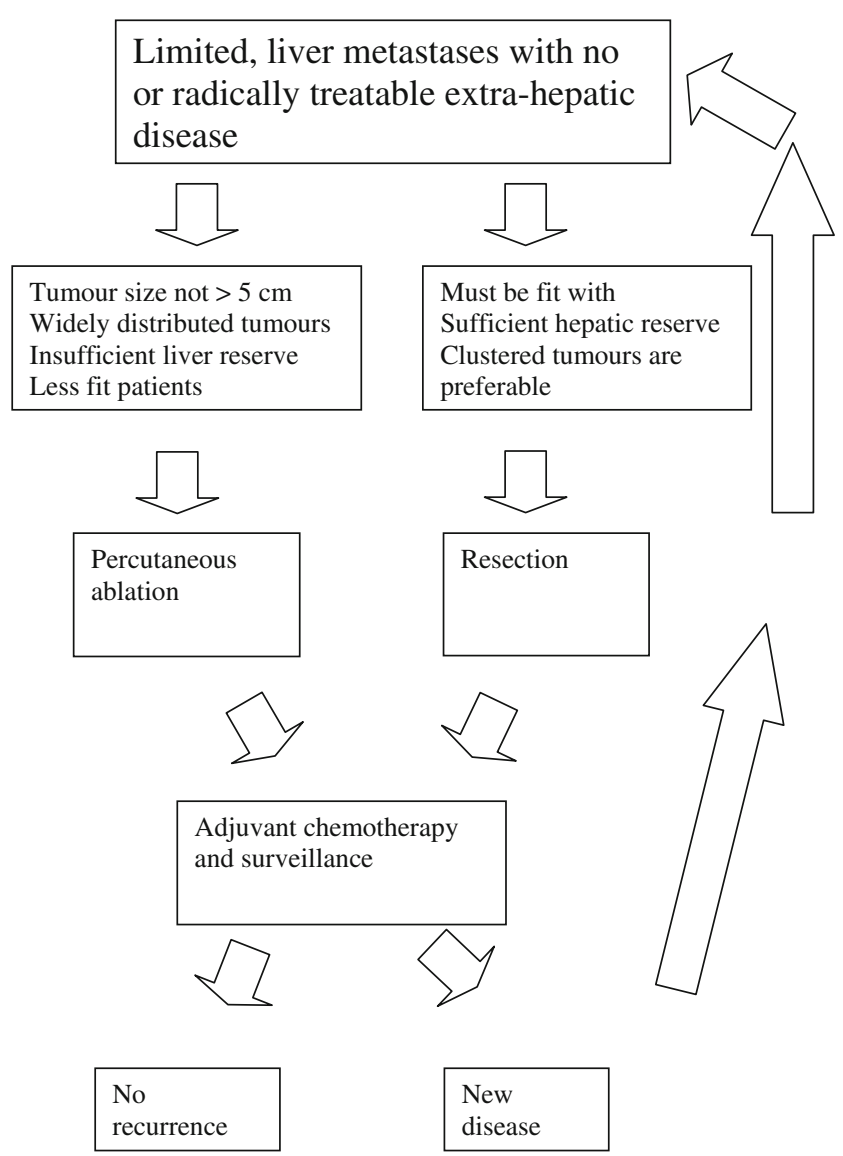

Fig. 2 Management algorithm for patients presenting with colorectal liver metastases

ablation arm were successfully downsized on chemotherapy, and subsequently underwent surgical resection [49]. This study suffered from slow accrual, was initially a phase III study but was downgraded to a phase II study, and closed early. As a result it was not sufficiently powered to allow assessment of differences in overall survival but did show significant differences in progression-free survival (PFS) at 3 years: $27.6 \%$ in the ablation arm versus $10.6 \%$ in the non-ablation arm $(p=0.025)$. The overall survival in the nonablation arm was much higher than expected and there were also significant differences in salvage therapy between the two groups with the non-ablation arm receiving more systemic treatment. Differences in overall survival at 30 months were not significant, but the survival curves continue to separate on follow-up; $47 \%$ versus $36 \%$ at 4 years and $40 \%$ versus $30 \%$ at 5 years.

The most common approach to patients presenting with non-resectable disease is to use downsizing with neoadjuvant chemotherapy followed by resection \pm portal vein embolisation and/or staged resection. However, the survival results of resection following portal vein embolisation are only $25 \%$ at 5 years [66]. Furthermore, nearly $40 \%$ of patients undergoing portal vein embolisation never get to resection and many patients planned for staged resection also fail to complete the course of treatment [67, 68]. Some, but not all, of these patients will have ablatable disease with comparable 5-year survival post-ablation but a higher chance of completing radical treatment to all sites of disease. Therefore, ablation should be considered in those with ablatable disease particularly if they fail to develop adequate liver volumes post-portal vein embolisation.

There is now general agreement that RF ablation is a useful adjunct to systemic treatment and it is widely applied in non-resectable but limited liver-only disease. For precise details on the appropriate tumour size, number and tumour location for ablation please see the section on tumour specific parameters.

Consensus level: strong

\section{Patients with non-resectable disease due to inadequate liver reserve either because of prior resection or widely scattered tumours}

Ablation is an accepted treatment for patients with small volume disease which cannot be resected due to limited liver reserve including most patients who have had a previous major liver resection [69]. Forty to $70 \%$ of patients will develop new metastases after even a successful resection, with clear margins on pathological analysis, and the majority cannot undergo repeat resection $[12,70,71]$. Ablation is indicated in those inoperable patients who have limited, liver-only disease with or without chemotherapy.

The authors advise that additional factors to be considered are:

- access, for example to a high left lobe liver remnant which may require a transthoracic approach

- the possibility of post-resection portal hypertension with low platelets and upper abdominal venous collaterals which may affect the chosen electrode trajectory

- the relationship of any tumour to a single remaining hepatic vein, portal vein branch or major bile duct that subtends a significant percentage of the remnant liver and could be damaged by ablation.

The risk of transient liver failure post-ablation in metastatic disease with a normal volume and normal functioning background liver parenchyma is very low and has only been described in two patients from a total cohort of $309(0.6 \%)$; both patients had undergone extended prior resection and at the time of ablation had only one and two remaining liver segments, respectively [4].

Consensus level: strong 


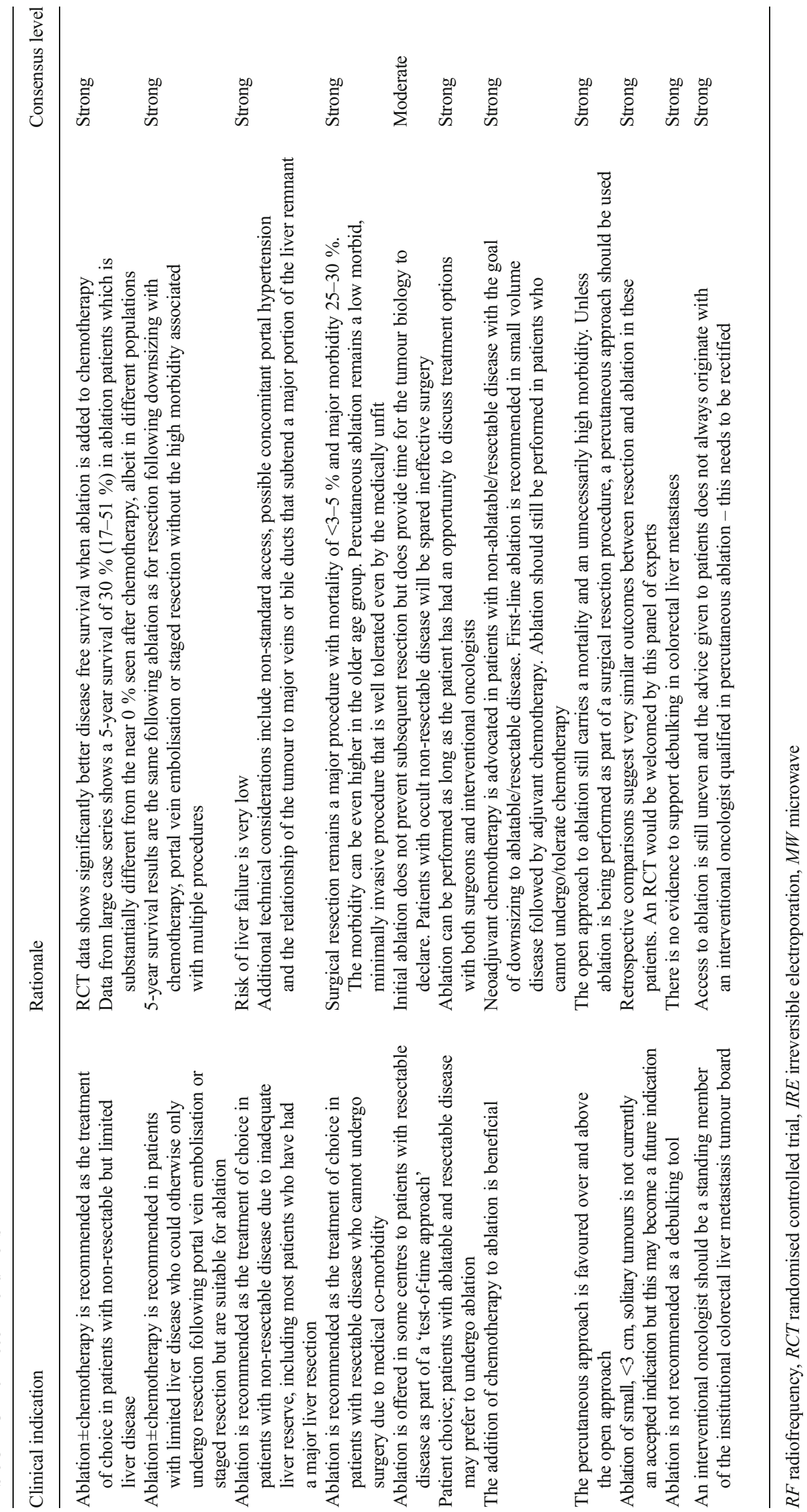


The role and approach to ablation in a patient with resectable disease but patient co-morbidity, for example cardiac, renal or respiratory disease, prevents a major procedure

Liver resection remains a major procedure which is not applicable to less fit patients. Liver resection still carries a finite mortality risk although mortality rates in experienced modern surgical practices should be less than $3 \%$ and certainly less than $5 \%$. Major morbidity is still high at approximately $25-$ $30 \%$. Morbidity can be even higher, up to $40 \%$, in the over 70 -year age group [72]. Percutaneous RF ablation is much less invasive, mortality is rare and major complication rates below $2.5 \%$ have been reported from several experienced centres $[29,31,36,39]$. All centres should aim for a major morbidity of $<5 \%$ and for the treatment of small volume disease (fewer than three tumours, $<3 \mathrm{~cm}$ in diameter) $<2 \%$. Both laparoscopic and open RF ablation carry a higher morbidity, require general anaesthesia, entail a longer hospital stay and increased cost, and should be reserved for specific indications. Open RF ablation without resection still carries a small mortality $(<2.3 \%)$ and the major complication rate varies between $9.6 \%$ and $32 \%$ (Table 2) [34, 41, 42]. Therefore the percutaneous approach is favoured. In more heavily morbid patients, ablation under moderate sedation may be preferable to GA.

Consensus level: strong

\section{Test-of-time approach}

The rationale for this approach is that ablation is often successful in treating small tumours without the need for resection but should ablation be unsuccessful, resection is still feasible. At the same time an interval is built into the patients' treatment programme so that as undetectable microscopic liver metastases enlarge, they become detectable on imaging. This apparent disease progression often changes the patient's status from resectable to unresectable. This test of time approach was first described in 2003 [63]. In that paper, of the 88 patients treated, $26 \%$ remained tumour-free, negating the need for resection, $50 \%$ developed more widespread disease progression and became unsuitable for resection, and $24 \%$ underwent resection. A modified test-of-time approach has been used by another group for poor risk patients, i.e. those who had positive margins at liver resection or those recurring within 6 months of liver resection [35]. The test-of-time approach was considered an acceptable application.

Consensus level: moderate

\section{Patient choice}

This indication applies to a small percentage of all patients undergoing RF ablation (2-19\%) [36, 37] who opt for ablation despite being suitable for resection. RF ablation can be undertaken with the proviso that patients should have had an opportunity to discuss the probable outcomes with each of the relevant specialties and in this way make a well informed decision.

Consensus level: strong

\section{What is the optimal timing of chemotherapy for patients receiving combined treatment?}

\section{Neoadjuvant chemotherapy}

Neoadjuvant chemotherapy is advocated in patients who are not suitable for ablation de novo, in the hope that downsizing will permit definitive treatment with resection or ablation. A 5 -year survival of $34 \%$ has been reported by one group using $\mathrm{RF}$ ablation in a small group of 36 patients following neoadjuvant chemotherapy [73]. A technical limitation to treating patients who have undergone neoadjuvant chemotherapy prior to ablation can be difficulty in visualising treated hepatic tumours for example because of the development of hepatosteatosis \pm tumour shrinkage. Additional techniques to define the tumours in the presence of chemotherapy-induced hepatosteatosis and tumour shrinkage,for example MRI with liver specific contrast agents, and larger treatment margins are recommended. Attempts to target and ablate tumours that are no longer visible on imaging using historical data and fusion techniques may be unsuccessful. However, tumours that have "disappeared' on imaging are still detectable in pathology specimens and as they enlarge are very likely to 're-appear' on follow-up imaging, so there should be a plan in place to treat these tumours when they do re-declare $[74,75]$.

\section{Adjuvant chemotherapy}

There is some evidence that adjuvant chemotherapy after liver resection maybe beneficial. A retrospective study in 235 patients showed a 5-year survival of $53 \%$ in a subgroup of 99 patients who received (mostly 5FU-leucovorin based) adjuvant chemotherapy versus $25 \%$ in those who did not have post-operative chemotherapy [76]. Two randomised studies, also using 5FU-leucovorin chemotherapy, showed a nonsignificant trend towards a benefit $(\mathrm{p}=0.125$ and 0.13 , respectively). When these studies were pooled the median relapsefree survival in the chemotherapy arm was 28 months versus 19 in the control arm $(\mathrm{p}=0.058)$ and the overall survival was 62 vs. 47 months $(p=0.095)$ [77, 78]. A randomised phase III trial of perioperative (six cycles prior followed by six cycles after resection) chemotherapy using FOLFOX (5FU and Oxaliplatin) showed a $7.3 \%$ increase in PFS at 3 years in the chemotherapy arm $(p=0.058)$ [79]. A recently published follow-up report of the same cohort at 8.5 years showed no 
difference in overall survival, but this regime is still recommended because of the improvement in PFS [80].

Similarly there is early data to support adjuvant chemotherapy after ablation. Machi et al. [33] studied RF ablation as a first-line treatment versus RF ablation following chemotherapy and showed an increased overall survival of 26 months (48 months for first-line RF ablation vs. 22 months for RF ablation after chemotherapy). However, this study was insufficiently powered for statistical analysis. Siperstein et al. [81] showed an overall survival of 28 months versus 19 months for those who received chemotherapy after laparoscopic ablation $(\mathrm{p}=0.02)$ and another paper reported a 10-year survival of $18 \%$ in patients treated with percutaneous ablation and adjuvant chemotherapy using 5FU and Irinotecan [36].

As percutaneous ablation carries a low morbidity, the interval between ablation and adjuvant chemotherapy can be less than after open ablation or resection, with many commencing chemotherapy approximately 2 weeks post-ablation.

Although more evidence needs to be acquired, ablation plus chemotherapy seems to be better than either ablation or chemotherapy alone. This is in line with animal data. In a series of laboratory studies, larger ablations were consistently achieved when a combination of Doxil and ablation was used as compared with thermal ablation alone [82, 83]. For patients with ablatable disease at presentation, adjuvant chemotherapy may be preferred to neoadjuvant chemotherapy. Patients who cannot undergo chemotherapy, for example due to significant co-morbidity, side effects or poor tolerance often tolerate ablation and should be considered for ablation if the size and location of their tumours is appropriate [7].

Consensus level: strong

\section{Can ablation be used to debulk liver metastases followed by chemotherapy?}

Surgical debulking is an established part of the management of some tumours, for example metastatic ovarian cancer. There has been some discussion in the surgical community of using resection to debulk colorectal metastases prior to systemic chemotherapy but this is not evidence-based. As a focal minimally invasive technique, ablation is a less effective debulking tool. It is therefore preferable to concentrate resources on performing ablation with curative intent in limited disease.

Consensus level: strong

\section{Choice of approach}

\section{Local recurrence}

A decrease in local recurrence rates following open ablation compared to other approaches has not been confirmed in all studies. Local recurrence following open ablation varies between $6 \%$ and $60 \%$ and following percutaneous ablation between $10 \%$ and $52 \%$ (Table 3) [44, 46, 84, 85]. All studies report lower rates of local recurrence in smaller tumours.

\section{Need for invasive staging}

One often quoted reason for an intra-operative approach is the need for invasive staging. There are several conflicting papers showing both a substantial and a minimal benefit from open or laparoscopic staging [86, 87]. In the current era of excellent preoperative staging with good quality CECT, MRI and PET-CT, the benefit of operative staging is likely to be very small [86].

We further stress the percutaneous approach is the least invasive method for performing ablation. Open ablation carries an increased mortality and morbidity over percutaneous ablation [34, 41, 42] and should be reserved for patients undergoing resection for un-ablatable disease including:

1) Bulk disease

2) Resection of multiple clustered tumours in one area with ablation to between one and four tumours in the remnant liver.

\section{Laparoscopic ablation}

This technique requires a high level of expertise but has been developed in a few centres who report a reduction in morbidity, cost and hospital stay as compared with open ablation (Table 2) $[5,30]$. Tumours that are adherent to vulnerable structures but are otherwise suitable for ablation may be best approached laparoscopically. However, a percutaneous approach should be favoured in tumours that are treatable either laparoscopically or percutaneously in order to minimise expense of hospital stay, morbidity and mortality $[7,30,32,40$, 43].

Consensus level: strong

\section{Access to Interventional Oncology ablation programmes and expertise}

An interventional oncologist qualified in percutaneous ablation should be a standing member of the institutional colorectal cancer liver metastasis tumour board making recommendations on management. We feel that the successful selection of patients suitable for tumour ablation is predicated on purposeful involvement of a qualified interventional oncologist in the decision making process.

Consensus level: strong 
Future indications for thermal ablation: can thermal ablation be used in resectable disease, in particular in small, solitary tumours, $<\mathbf{3} \mathbf{~ c m}$ in diameter?

The old mantra that the only chance of cure lies with resection is no longer true. Thermal ablation can and does result in cure in selected patients $[42,88]$.

Whilst there are several retrospective studies showing better survival following resection than following ablation, the two techniques are nearly always applied selectively with ablation being used in the patient group who are expected to fare less well $[5,85]$. More often than not the ablation group has more disease, including extra-hepatic disease, is older and has more co-morbidities, or attempts have been made to ablate larger, $>5-\mathrm{cm}$, tumours which are unlikely to succeed. When ablation has been applied as first-line therapy to patients with resectable disease, the 5-year survival results have been very similar to surgical series $[30,61]$.

Although there is one study showing comparable local tumour progression between wedge resection, anatomical resection and ablation [45], most surgical series report higher local tumour progression following ablation than after resection [43]. Despite this the overall survival is often similar [34].

There are five retrospective studies that show comparable survival between resection and ablation particularly when ablation is applied to smaller, $<3-\mathrm{cm}$ tumours. The results from Kim, Otto and Reuter have already been discussed [32, 34, 61]. Two other, smaller series also showed comparable results. Hur [89] reported on 23 patients who underwent resection compared with 15 who underwent either percutaneous or intraoperative RF ablation for $<=3$-cm tumours. The 5 -year survival was $56 \%$ and $55 \%$, respectively. Oshowo [90] compared resection and percutaneous ablation in solitary tumours of any size and found a similar 3-year survival. All of these studies are relatively small; more evidence is required. The possibility of a prospective RCT between surgical resection and ablation has been debated for over a decade and would be welcomed by this panel of experts. Likewise we would call for direct comparison to other therapies, for example chemo/ radioembolisation or focal radiation therapy.

Consensus level: strong

\section{Future directions}

The gold standard RCT data, is very difficult to achieve and expensive. Vested interests, evolving technologies and patient resistance to randomisation are substantial barriers. The only attempted randomised trial of chemotherapy \pm ablation (EORTC 40004) failed to accrue and the authors concluded that the chances of a further RCT were minimal. In addition changes in chemotherapy over the time-course of the study and significant differences in salvage therapy meant the initial endpoints and statistical framework proved inadequate.

In the interim, more, clearer and cleaner published data are required. Papers dealing with one tumour type, for example colorectal or breast liver metastases rather than mixed tumour populations, uniform technologies and approaches, larger series, more patient details and more specific patient groups are required to clarify what ablation can offer, and local recurrence rates should be reduced. Patients need better access to ablation programmes and to interventional oncology expertise.

\section{Conclusion}

Thermal ablation is widely, but not universally, accepted as part of the management of patients with unresectable colorectal liver metastases. Not all patients who are suitable for ablation have access to good quality ablation expertise. Furthermore, ablation has not yet reached its full potential; more can be done. It is our intention that these recommendations will facilitate the judicious selection of the patients who are most likely to benefit from ablation therapy and provide a unified interventional oncology perspective as we attempt to generate greater consensus from other oncology disciplines for the use of this clearly beneficial technology.

Acknowledgments The scientific guarantor of this publication is Dr. Gigi Solbiait. The authors of this manuscript declare relationships with the following companies: Angiodynamics, Bayer, Boston Scientific, Bracco, BTG and Biocompatibles, Celon-Olympus, CeloNova, Celsion, Cosman Company, Covidien, Endocare, Esaote, Ethicon, Galil, GE Heathcare Gore, Microsulis, Neuwave Medical, Perfint, Pharmacept, Phillips Healthcare, Samsung, Siemens, Terumo. The authors state that this work has not received any funding. No complex statistical methods were necessary for this paper. Institutional Review Board approval and written informed consent were not required for this study because this is a review of existing published work.

Some study subjects or cohorts have been previously reported in a number of different journals as this is a review of the literature. Methodology: retrospective, not applicable, multicentre study.

Open Access This article is distributed under the terms of the Creative Commons Attribution-NonCommercial 4.0 International License (http:// creativecommons.org/licenses/by-nc/4.0/), which permits any noncommercial use, distribution, and reproduction in any medium, provided you give appropriate credit to the original author(s) and the source, provide a link to the Creative Commons license, and indicate if changes were made.

\section{References}

1. Steward BW, Kleihues P (eds) (2003) Colorectal Cancer. World Cancer Report IACR Press;198-202

2. Choti MA, Sitzmann JV, Tiburi MF, Sumetchotimetha W, Rangsin R, Schulick RD, Lillemoe KD, Yeo CJ, Cameron JL (2002) Trends 
in long-term survival following liver resection for hepatic colorectal metastases. Ann Surg :759-66

3. Kornprat P, Jarnagin WR, Gonen M, Dematteo RP, Fong Y, Blumgart LH, D'Angelica M (2007) Outcome after hepatectomy for multiple (four or more) colorectal metastases in the era of effective chemotherapy. Ann Surg Oncol :1151-60

4. Abdalla EK, Vauthey JN, Ellis LM, Ellis V, Pollock R, Broglio KR, Hess K, Curley SA (2004) Recurrence and outcomes following hepatic resection, radiofrequency ablation, and combined resection/ablation for colorectal liver metastases. Ann Surg :818-25

5. Agcaoglu O, Aliyev S, Karabulut K, El Gazzaz G, Aucejo F, Pelley R, Siperstein AE, Berber E (2013) Complementary use of resection and radiofrequency ablation for the treatment of colorectal liver metastases: an analysis of 395 patients. World J Surg :1333-9

6. Bale R, Widmann G, Schullian P, Haidu M, Pall G, Klaus A, Weiss H, Biebl M, Margreiter R (2012) Percutaneous stereotactic radiofrequency ablation of colorectal liver metastases. Eur Radiol :930-7

7. Gillams AR, Lees WR (2009) Five-year survival in 309 patients with colorectal liver metastases treated with radiofrequency ablation. Eur Radiol :1206-13

8. Lorentzen T (1996) A cooled needle electrode for radiofrequency tissue ablation: thermodynamic aspects of improved performance compared with conventional needle design. Acad Radiol :556-63

9. Goldberg SN, Solbiati L, Hahn PF, Cosman E, Conrad JE, Fogle R, Gazelle GS (1998) Large-volume tissue ablation with radio frequency by using a clustered, internally cooled electrode technique: laboratory and clinical experience in liver metastases. Radiology : 371-9

10. Oshowo A, Gillams AR, Lees WR, Taylor I (2003) Radiofrequency ablation extends the scope of surgery in colorectal liver metastases. Eur J Surg Oncol :244-7

11. Evrard S, Becouarn Y, Fonck M, Brunet R, Mathoulin-Pelissier S, Picot V (2004) Surgical treatment of liver metastases by radiofrequency ablation, resection, or in combination. Eur J Surg Oncol : 399-406

12. de Jong MC, Pulitano C, Ribero D, Strub J, Mentha G, Schulick RD, Choti MA, Aldrighetti L, Capussotti L, Pawlik TM (2009) Rates and patterns of recurrence following curative intent surgery for colorectal liver metastasis: an international multi-institutional analysis of 1669 patients. Ann Surg :440-8

13. Hompes D, Prevoo W, Ruers T (2011) Radiofrequency ablation as a treatment tool for liver metastases of colorectal origin. Cancer Imaging :23-30

14. Cirocchi R, Trastulli S, Boselli C, Montedori A, Cavaliere D, Parisi A, Noya G, Abraha I. (2012) Radiofrequency ablation in the treatment of liver metastases from colorectal cancer. Cochrane Database Syst Rev;CD006317

15. Pathak S, Jones R, Tang JM, Parmar C, Fenwick S, Malik H, Poston G (2011) Ablative therapies for colorectal liver metastases: a systematic review. Color Dis;e252-e265

16. Nesbitt C, Glendinning RJ, Byrne C, Poston GJ (2007) Factors that influence treatment strategies in advanced colorectal cancer. Eur J Surg Oncol;:S88-S94

17. Weng M, Zhang Y, Zhou D, Yang Y, Tang Z, Zhao M, Quan Z, Gong W (2012) Radiofrequency ablation versus resection for colorectal cancer liver metastases: a meta-analysis. PLoS One;e45493

18. Minami Y, Kudo M (2013) Radiofrequency ablation of liver metastases from colorectal cancer: a literature review. Gut Liver :1-6

19. Khajanchee YS, Hammill CW, Cassera MA, Wolf RF, Hansen PD (2011) Hepatic resection vs minimally invasive radiofrequency ablation for the treatment of colorectal liver metastases: a Markov analysis. Arch.Surg :1416-23

20. Jones C, Badger SA, Ellis G (2011) The role of microwave ablation in the management of hepatic colorectal metastases. Surgeon :33-7

21. Brouquet A, Andreou A, Vauthey JN (2011) The management of solitary colorectal liver metastases. Surgeon :265-72
22. Stang A, Fischbach R, Teichmann W, Bokemeyer C, Braumann D (2009) A systematic review on the clinical benefit and role of radiofrequency ablation as treatment of colorectal liver metastases. Eur J Cancer : 1748-56

23. Smith MD, McCall JL (2009) Systematic review of tumour number and outcome after radical treatment of colorectal liver metastases. Br J Surg :1101-13

24. Curley SA (2008) Radiofrequency ablation versus resection for resectable colorectal liver metastases: time for a randomized trial? Ann Surg Oncol :11-3

25. Mulier S, Ruers T, Jamart J, Michel L, Marchal G, Ni Y (2008) Radiofrequency ablation versus resection for resectable colorectal liver metastases: time for a randomized trial? An update. Dig Surg : 445-60

26. Sutherland LM, Williams JA, Padbury RT, Gotley DC, Stokes B, Maddern GJ (2006) Radiofrequency ablation of liver tumors: a systematic review. Arch Surg :181-90

27. Hildebrand P, Leibecke T, Kleemann M, Mirow L, Birth M, Bruch HP, Burk C (2006) Influence of operator experience in radiofrequency ablation of malignant liver tumours on treatment outcome. Eur J Surg Oncol :430-4

28. Mulier S, Ni Y, Jamart J, Ruers T, Marchal G, Michel L (2005) Local recurrence after hepatic radiofrequency coagulation: multivariate meta-analysis and review of contributing factors. Ann Surg : $158-71$

29. Hamada A, Yamakado K, Nakatsuka A, Uraki J, Kashima M, Takaki H, Yamanaka T, Inoue Y, Kusunoki M, Takeda K (2012) Radiofrequency ablation for colorectal liver metastases: prognostic factors in non-surgical candidates. Jpn J Radiol :567-74

30. Hammill CW, Billingsley KG, Cassera MA, Wolf RF, Ujiki MB, Hansen PD (2011) Outcome after laparoscopic radiofrequency ablation of technically resectable colorectal liver metastases. Ann Surg Oncol : 1947-54

31. Jakobs TF, Hoffmann RT, Trumm C, Reiser MF, Helmberger TK (2006) Radiofrequency ablation of colorectal liver metastases: midterm results in 68 patients. Anticancer Res :671-80

32. Kim KH, Yoon YS, Yu CS, Kim TW, Kim HJ, Kim PN, Ha HK, Kim JC (2011) Comparative analysis of radiofrequency ablation and surgical resection for colorectal liver metastases. J Korean Surg Soc :25-34

33. Machi J, Oishi AJ, Sumida K, Sakamoto K, Furumoto NL, Oishi RH, Kylstra JW (2006) Long-term outcome of radiofrequency ablation for unresectable liver metastases from colorectal cancer: evaluation of prognostic factors and effectiveness in first- and secondline management. Cancer J :318-26

34. Reuter NP, Woodall CE, Scoggins CR, McMasters KM, Martin RC (2009) Radiofrequency ablation vs. resection for hepatic colorectal metastasis: therapeutically equivalent? J Gastrointest Surg :486-91

35. Sofocleous CT, Petre EN, Gonen M, Brown KT, Solomon SB, Covey AM, Alago W, Brody LA, Thornton RH, D'Angelica M, Fong Y, Kemeny NE (2011) CT-guided radiofrequency ablation as a salvage treatment of colorectal cancer hepatic metastases developing after hepatectomy. J Vasc Interv Radiol :755-61

36. Solbiati L, Ahmed M, Cova L, Ierace T, Brioschi M, Goldberg SN (2012) Small liver colorectal metastases treated with percutaneous radiofrequency ablation: local response rate and long-term survival with up to 10-year follow-up. Radiology :958-68

37. Sorensen SM, Mortensen FV, Nielsen DT (2007) Radiofrequency ablation of colorectal liver metastases: long-term survival. Acta Radiol :253-8

38. van Tilborg AA, Meijerink MR, Sietses C, van Waesberghe JH, Mackintosh MO, Meijer S, Van Kuijk C, van den TP (2011) Long-term results of radiofrequency ablation for unresectable colorectal liver metastases: a potentially curative intervention. Br.J Radiol :556-65 
39. Veltri A, Sacchetto P, Tosetti I, Pagano E, Fava C, Gandini G (2008) Radiofrequency ablation of colorectal liver metastases: small size favorably predicts technique effectiveness and survival. Cardiovasc.Intervent.Radiol :948-56

40. Mulier S, Mulier P, Ni Y, Miao Y, Dupas B, Marchal G, De W, I, Michel L (2002) Complications of radiofrequency coagulation of liver tumours. Br J Surg :1206-22

41. McKay A, Fradette K, Lipschitz J (2009) Long-term outcomes following hepatic resection and radiofrequency ablation of colorectal liver metastases. HPB Surg :346863

42. Nielsen K, van Tilborg AA, Meijerink MR, Macintosh MO, Zonderhuis BM, de Lange ES, Comans EF, Meijer S, van den Tol MP (2013) Incidence and treatment of local site recurrences following RFA of colorectal liver metastases. World J Surg :1340-7

43. White RR, Avital I, Sofocleous CT, Brown KT, Brody LA, Covey A, Getrajdman GI, Jarnagin WR, Dematteo RP, Fong Y, Blumgart LH, D'Angelica M (2007) Rates and patterns of recurrence for percutaneous radiofrequency ablation and open wedge resection for solitary colorectal liver metastasis. J Gastrointest Surg :256-63

44. De Baere T, Elias D, Dromain C, Din MG, Kuoch V, Ducreux M, Boige V, Lassau N, Marteau V, Lasser P, Roche A (2000) Radiofrequency ablation of 100 hepatic metastases with a mean follow-up of more than 1 year. AJR Am J Roentgenol :1619-25

45. Elias D, Baton O, Sideris L, Matsuhisa T, Pocard M, Lasser P (2004) Local recurrences after intraoperative radiofrequency ablation of liver metastases: a comparative study with anatomic and wedge resections. Ann Surg Oncol :500-5

46. van Duijnhoven FH, Jansen MC, Junggeburt JM, van Hillegersberg R, Rijken AM, Van Coevorden F, van dS, Jr., van Gulik TM, Slooter GD, Klaase JM, Putter H, Tollenaar RA (2006) Factors influencing the local failure rate of radiofrequency ablation of colorectal liver metastases. Ann Surg Oncol :651-8

47. Wang X, Sofocleous CT, Erinjeri JP, Petre EN, Gonen M, Do KG, Brown KT, Covey AM, Brody LA, Alago W, Thornton RH, Kemeny NE, Solomon SB (2013) Margin size is an independent predictor of local tumor progression after ablation of colon cancer liver metastases. Cardiovasc Intervent Radiol :166-75

48. Gillams AR, Lees WR (2004) Radio-frequency ablation of colorectal liver metastases in 167 patients. Eur Radiol :2261-7

49. Ruers T, Punt C, Van Coevorden F, Pierie JP, Borel-Rinkes I, Ledermann JA, Poston G, Bechstein W, Lentz MA, Mauer M, Van Cutsem E, Lutz MP, Nordlinger B (2012) Radiofrequency ablation combined with systemic treatment versus systemic treatment alone in patients with non-resectable colorectal liver metastases: a randomized EORTC Intergroup phase II study (EORTC 40004). Ann Oncol :2619-26

50. Gillams AR, Lees WR (2008) Five-year survival following radiofrequency ablation of small, solitary, hepatic colorectal metastases. J Vasc Interv Radiol 712-7

51. Marchal F, Elias D, Rauch P, Leroux A, Stines J, Verhaeghe JL, Guillemin F, Villemot JP (2004) Biliary lesions during radiofrequency ablation in liver. Study on the pig. Eur Surg Res :88-94

52. Ogawa T, Kawamoto H, Kobayashi Y, Nakamura S, Miyatake H, Harada R, Tsutsumi K, Fujii M, Kurihara N, Kato H, Hirao K, Mizuno O, Ishida E, Okada H, Yamamoto K (2010) Prevention of biliary complication in radiofrequency ablation for hepatocellular carcinoma-Cooling effect by endoscopic nasobiliary drainage tube. Eur J Radiol :385-90

53. Silk MT, Wimmer T, Lee KS, Srimathveeravalli G, Brown KT, Kingham PT, Fong Y, Durack JC, Sofocleous CT, Solomon SB (2013) Percutaneous Ablation of Peribiliary Tumors with Irreversible Electroporation. J Vasc Interv Radiol

54. Kingham TP, Karkar AM, D'Angelica MI, Allen PJ, Dematteo RP, Getrajdman GI, Sofocleous CT, Solomon SB, Jarnagin WR, Fong Y (2012) Ablation of perivascular hepatic malignant tumors with irreversible electroporation. J Am Coll Surg :379-87
55. Gillams A, Lees W (2003) Liver Isolation during Radiofrequency Ablation of Liver Tumours. Radiology. Ref Type: Abstract

56. Ginat DT, Saad W, Davies M, Walman D, Erturk E (2009) Bowel displacement for CT-guided tumor radiofrequency ablation: techniques and anatomic considerations. J Endourol :1259-64

57. Lee SJ, Choyke LT, Locklin JK, Wood BJ (2006) Use of hydrodissection to prevent nerve and muscular damage during radiofrequency ablation of kidney tumors. J Vasc Interv Radiol : 1967-9

58. Gillams A, Khan Z, Osborn P, Lees W (2012) Survival after Radiofrequency Ablation in 122 Patients with Inoperable Colorectal Lung Metastases. Cardiovasc Intervent Radiol

59. Yamakado K, Inoue Y, Takao M, Takaki H, Nakatsuka A, Uraki J, Kashima M, Kusunoki M, Shimpo H, Takeda K (2009) Long-term results of radiofrequency ablation in colorectal lung metastases: single center experience. Oncol Rep :885-91

60. Yan TD, King J, Sjarif A, Glenn D, Steinke K, Morris DL (2006) Learning curve for percutaneous radiofrequency ablation of pulmonary metastases from colorectal carcinoma: a prospective study of 70 consecutive cases. Ann Surg Oncol :1588-95]

61. Otto G, Duber C, Hoppe-Lotichius M, Konig J, Heise M, Pitton MB (2010) Radiofrequency ablation as first-line treatment in patients with early colorectal liver metastases amenable to surgery. Ann.Surg. : 796-803

62. Liu Z, Ahmed M, Sabir A, Humphries S, Goldberg SN (2007) Computer modeling of the effect of perfusion on heating patterns in radiofrequency tumor ablation. Int J Hyperth :49-58

63. Livraghi T, Solbiati L, Meloni F, Ierace T, Goldberg SN, Gazelle GS (2003) Percutaneous radiofrequency ablation of liver metastases in potential candidates for resection: the "test-of-time approach". Cancer :3027-35

64. Claudon M, Dietrich CF, Choi BI, Cosgrove DO, Kudo M, Nolsoe CP, Piscaglia F, Wilson SR, Barr RG, Chammas MC, Chaubal NG, Chen MH, Clevert DA, Correas JM, Ding H, Forsberg F, Fowlkes JB, Gibson RN, Goldberg BB, Lassau N, Leen EL, Mattrey RF, Moriyasu F, Solbiati L, Weskott HP, Xu HX (2013) Guidelines and good clinical practice recommendations for contrast enhanced ultrasound (CEUS) in the liver-update 2012: a WFUMB-EFSUMB initiative in cooperation with representatives of AFSUMB, AIUM, ASUM, FLAUS and ICUS. Ultraschall Med :11-29

65. Desot E, de Mestier L, Volet J, Delmas C, Garcia B, Geoffroy P, Abdelli N, Baule M, Dubroeucq O, Marquis E, Bouche O (2013) Prognostic factors in patients with non resectable metastatic colorectal cancer in the era of targeted biotherapies: relevance of Kohne's risk classification. Dig Liver Dis. :330-5

66. Pamecha V, Glantzounis G, Davies N, Fusai G, Sharma D, Davidson B (2009) Long-term survival and disease recurrence following portal vein embolisation prior to major hepatectomy for colorectal metastases. Ann Surg Oncol :1202-7

67. Pamecha V, Nedjat-Shokouhi B, Gurusamy K, Glantzounis GK, Sharma D, Davidson BR (2008) Prospective evaluation of two-stage hepatectomy combined with selective portal vein embolisation and systemic chemotherapy for patients with unresectable bilobar colorectal liver metastases. Dig Surg :387-93

68. Shindoh J, Tzeng CW, Aloia TA, Curley SA, Zimmitti G, Wei SH, Huang SY, Gupta S, Wallace MJ, Vauthey JN (2013) Portal vein embolization improves rate of resection of extensive colorectal liver metastases without worsening survival. Br J Surg :1777-83

69. Elias D, de Baere T, Smayra T, Ouellet JF, Roche A, Lasser P (2002) Percutaneous radiofrequency thermoablation as an alternative to surgery for treatment of liver tumour recurrence after hepatectomy. Br J Surg :752-6

70. Chan KM, Chiang JM, Lee CF, Yu MC, Lee WC, Chen JS, Wang JY (2011) Outcomes of resection for colorectal cancer 
hepatic metastases stratified by evolving eras of treatment. World J Surg Oncol 174

71. Vigano L, Capussotti L, Lapointe R, Barroso E, Hubert C, Giuliante F, Ijzermans JN, Mirza DF, Elias D, Adam R (2014) Early Recurrence After Liver Resection for Colorectal Metastases: Risk Factors, Prognosis, and Treatment. A LiverMetSurvey-Based Study of 6,025 Patients. Ann Surg Oncol ;1276-86

72. de Liguori $\mathrm{CN}$, van Leeuwen BL, Ghaneh P, Wu A, Audisio RA, Poston GJ (2008) Liver resection for colorectal liver metastases in older patients. Crit Rev Oncol Hematol :273-8

73. Knudsen AR, Kannerup AS, Mortensen FV, Nielsen DT (2009) Radiofrequency ablation of colorectal liver metastases downstaged by chemotherapy. Acta Radiol :716-21

74. Adam R, Vibert E, Pitombo M (2006) [Induction chemotherapy and surgery of colorectal liver metastases]. Bull Cancer;S45-S49

75. Tanaka K, Adam R, Shimada H, Azoulay D, Levi F, Bismuth H (2003) Role of neoadjuvant chemotherapy in the treatment of multiple colorectal metastases to the liver. Br J Surg :963-9

76. Figueras J, Valls C, Rafecas A, Fabregat J, Ramos E, Jaurrieta E (2001) Resection rate and effect of postoperative chemotherapy on survival after surgery for colorectal liver metastases. Br J Surg : 980-5

77. Portier G, Elias D, Bouche O, Rougier P, Bosset JF, Saric J, Belghiti J, Piedbois P, Guimbaud R, Nordlinger B, Bugat R, Lazorthes F, Bedenne L (2006) Multicenter randomized trial of adjuvant fluorouracil and folinic acid compared with surgery alone after resection of colorectal liver metastases: FFCD ACHBTH AURC 9002 trial. J Clin Oncol :4976-82

78. Mitry E, Fields AL, Bleiberg H, Labianca R, Portier G, Tu D, Nitti D, Torri V, Elias D, O'Callaghan C, Langer B, Martignoni G, Bouche O, Lazorthes F, Van Cutsem E, Bedenne L, Moore MJ, Rougier P (2008) Adjuvant chemotherapy after potentially curative resection of metastases from colorectal cancer: a pooled analysis of two randomized trials. J Clin Oncol :4906-11

79. Nordlinger B, Sorbye H, Glimelius B, Poston GJ, Schlag PM, Rougier P, Bechstein WO, Primrose JN, Walpole ET, Finch-Jones M, Jaeck D, Mirza D, Parks RW, Collette L, Praet M, Bethe U, Van Cutsem E, Scheithauer W, Gruenberger T (2008) Perioperative chemotherapy with FOLFOX4 and surgery versus surgery alone for resectable liver metastases from colorectal cancer (EORTC Intergroup trial 40983): a randomised controlled trial. Lancet : $1007-16$

80. Nordlinger B, Sorbye H, Glimelius B, Poston GJ, Schlag PM, Rougier P, Bechstein WO, Primrose JN, Walpole ET, Finch-Jones
M, Jaeck D, Mirza D, Parks RW, Mauer M, Tanis E, Van Cutsem E, Scheithauer W, Gruenberger T (2013) Perioperative FOLFOX4 chemotherapy and surgery versus surgery alone for resectable liver metastases from colorectal cancer (EORTC 40983): long-term results of a randomised, controlled, phase 3 trial. Lancet Oncol : $1208-15$

81. Siperstein AE, Berber E, Ballem N, Parikh RT (2007) Survival after radiofrequency ablation of colorectal liver metastases: 10-year experience. Ann Surg. :559-65

82. Ahmed M, Goldberg SN (2004) Combination radiofrequency thermal ablation and adjuvant IV liposomal doxorubicin increases tissue coagulation and intratumoural drug accumulation. Int J Hyperth :781-802

83. Goldberg SN, Kamel IR, Kruskal JB, Reynolds K, Monsky WL, Stuart KE, Ahmed M, Raptopoulos V (2002) Radiofrequency ablation of hepatic tumors: increased tumor destruction with adjuvant liposomal doxorubicin therapy. AJR Am J Roentgenol :93-101

84. Elias D, Baton O, Sideris L, Boige V, Malka D, Liberale G, Pocard M, Lasser P (2005) Hepatectomy plus intraoperative radiofrequency ablation and chemotherapy to treat technically unresectable multiple colorectal liver metastases. J Surg Oncol :36-42

85. Gleisner AL, Choti MA, Assumpcao L, Nathan H, Schulick RD, Pawlik TM (2008) Colorectal liver metastases: recurrence and survival following hepatic resection, radiofrequency ablation, and combined resection-radiofrequency ablation. Arch Surg :1204-12

86. Bickenbach KA, Dematteo RP, Fong Y, Peter KT, Allen PJ, Jarnagin WR, D'Angelica MI (2013) Risk of occult irresectable disease at liver resection for hepatic colorectal cancer metastases: a contemporary analysis. Ann Surg Oncol :2029-34

87. Pilkington SA, Rees M, Peppercorn D, John TG (2007) Laparoscopic staging in selected patients with colorectal liver metastases as a prelude to liver resection. HPB (Oxford) :58-63

88. Abitabile P, Hartl U, Lange J, Maurer CA (2007) Radiofrequency ablation permits an effective treatment for colorectal liver metastasis. Eur J Surg Oncol. :67-71

89. Hur H, Ko YT, Min BS, Kim KS, Choi JS, Sohn SK, Cho CH, Ko HK, Lee JT, Kim NK (2009) Comparative study of resection and radiofrequency ablation in the treatment of solitary colorectal liver metastases. Am J Surg :728-36

90. Oshowo A, Gillams A, Harrison E, Lees WR, Taylor I (2003) Comparison of resection and radiofrequency ablation for treatment of solitary colorectal liver metastases. Br J Surg : $1240-3$ 